\title{
Antimicrobial activity of Camels (Camelusdromedarius ) and Sheep urine on some pathogenic bacteria .
}

\author{
Sumia A. D ${ }^{1 *}$, Ali A. Majid ${ }^{2}$ Muna E. A \\ ${ }^{1 *}$ Department of Viral Vaccines, Veterinary Research Institute, Animal Resources Research \\ Corporation, P.O.Box 8067, ALAmarat, Khartoum, Sudan. \\ 2 Graduate studies, OmdermanAhlia University . P .O. Box 4102 Khartoum Central \\ Sudan. \\ 3 Department of Bacteriology Veterinary Research Institute, Animal Resources Research \\ Corporation, P.O.Box 8067, ALAmarat, Khartoum, Sudan.
}

\begin{abstract}
:
Aims: This study was designed to investigate the antimicrobial effect of camel and sheep urine to Staph aureus (S.aureus), Escherichia coli (E. coli). Salmonella SP, Pseudomonas aeruginosa (ps. Aeruginosa) and Enterobacter cloacae (E. cloacae).

Study Design: a total of 100 samples of urine (60 from camels and 40 from sheep) collected fromdifferent localities in Sudan including:Tampool, Elobied and Batana slaughter houses were tested for antimicrobial activity to some bacterial isolates.

Place and Duration of Study: The study was undertaken in the Bacteriology lab, Veterinary Research Institute, Ministry of Animal Resources, Fisheries and Range Lands, Khartoum during 2014-2015.

Methodology: Disc diffusion and Agar well diffusion methods were used.

Results: clear Zones of inhibition were observed onto S. aureus. E. coli. , Salmonella SP, PS. aeruginosa and E. cloacae when tested using camel urine.

Conclusion: Concentrated camel urine was reported as the best preparation of camel urine with high ability to inhibit bacterial growth.
\end{abstract}

\section{Introduction}

The camel is a multipurpose livestock species of great economic importance due to the benefits provided by camel products. camels are well adapted to heat and arid environment, desertification, and scarce natural resources. They are a source of high value meat and milk for the population in arid areas and provide efficient services in agriculture, transport and leisure [1].Early Arabs boiled camel urine and drank it to cure some internal disease problems such as fasciolosis and for correcting disorders in general, particularly hepatitis, liver swelling, abscesses [2,3].Research on camel was intensified since the late seventies as it has been found to endure more efficiently the draught of that period more than any other animal species. Emphasis on research was directed towards diseases production and reproduction. Over recent years, new areas of research have addressed the potential role of camel products such as milk and metabolic excretions such as urine in the treatment of human diseases. Camel immunoglobulin antibodies have also shown a good potential for the management and control of human diseases such as cancer as well as their application in the diagnosis and production of chemotherapy to resistant pathogens. Over recent years, the increase in microbial diseases created ever bigger challenge for antimicrobial therapy. Proper natural drugs are identified as one of essential elements of primary healthcare. Natural products play an important role in our health care system. They offer a valuable source of potent compounds with a wide variety of biological activities and novel chemical structures, many of which might be important for novel drug development [3,4]. Among these drugs are camel and sheep urine which are believed to contain therapeutic and antimicrobial factors. Since long time ago camel was recognized as a valuable animal with therapeutic products such as milk and urine and has been used traditionally in the treatment of many diseases in the Arab countries [5].

\section{1. Collection of samples:}

\section{Material And Methods}

A total of 100 samples of urine (60 from camels and 40 from sheep) were collected in the morning during 2014 to 2015 from different areas of Sudan (Tampool ,Elobied, Batana slaughter house), from healthy males and females (Camelusdromedarius ) and sheep with ages ranging from 4 month to 4 year. These sample were collected aseptically by taking the whole urinary bladder swabbing the surface with $70 \%$ alcohol, then using syringes, $5 \mathrm{ml}$ of urine was transferred aseptically into sterile bijou's bottles. 
Antimicrobial activity of Camels (Camelusdromedarius) and Sheep urine on some pathogenic ..

\section{2. Sensitivity test using Camel/Sheep urine as antimicrobial:}

Sensitivity of bacterial species was tested on Mueller Hinton agar medium against camel and sheep urine. These species were S. aureus. E.coli., Salmonella SP, Pseudomonas aeruginosa and E. cloacae. The previous bacterial isolates are standard strains unless salmonella sp which isolated form an outbreak in poultry farm.

Two methods were used in this study.

\section{2. Disc diffusion methods:}

According to Buxton and fraser,[6]discs of $6 \mathrm{~mm}$ diameter form sheet of thick filter paper (what man No1) were punched out using paper drill, sterilized hot air oven at $160{ }^{\circ} \mathrm{C}$ for $30 \mathrm{~min}$ then impregnated in the tests camel/ sheep urine samples [6]. The tested organisms were cultured in normal saline then diluted to a density visually equivalent to $0.5 \mathrm{MacFarlane}$ that was prepared by adding $0.5 \mathrm{ml}$ of percent $\mathrm{BaCl}_{2}$ to 99.5 of $\mathrm{I}$ percent $\mathrm{H}_{2} \mathrm{SO}_{4}$ approximately [7].

The plates of Mueller Hinton Agar were dried in incubator for $30 \mathrm{~min}$; few drops of diluted culture of the tested organisms were floated on the medium and distributed all over the plate, to ensure good growth plates were letto dry for 5 min.Using forceps discs were gently pressed down to ensure better contact with the agar.The plates were incubated at $37^{\circ} \mathrm{C}$ for 24 hours. The zones of growth inhibition were measured as a diameter from the edge to edge of the clear area using ruler.

\section{2. 2. Agar well diffusion:}

According to standard method by Perez [8], Plates of Muller Hinton Agar were cultured by the tested organism, then wells of $8 \mathrm{~mm}$ diameter were punched into in the agar using sterilized well cutter. The wells were filled with urine, one well filled with sterile distilled water as control, and then the plates were incubated at $37{ }^{\circ} \mathrm{C}$ for 24 to 48 hours. The antimicrobial activity was evaluated by measuring the zone of inhibition around the well. The same steps of previous method were fallowed using:

1- Normal urine\&

2- Neutralized urine

camel / sheep urine adjusted to neutral $\mathrm{PH}$ by adding $\mathrm{HCl}(10 \%)$ to decrease the $\mathrm{PH}$ (the $\mathrm{PH}$ of camel urine samples were alkaline 9-14) until it was 7.1.

3- Concentrated urine.

$200 \mathrm{ml}$ camel urine, $100 \mathrm{ml}$ sheep urine were used, Boiled to $100{ }^{\circ} \mathrm{C}$ until it was $20 \%$.

\section{Results}

Several trails were conducted to find out the best preparation of camels and sheep's urine with ability of inhibition of bacterial growth, starting from untreated (normal) fresh urine then neutralized urine and finally by highly concentrated urine (after boiling until 20\%), we noted that the last one resulted in clear zones of inhibition on all bacteria above especially Ps. aeruginosa .

Concentrated camel urine was reported as the best preparation of camel urine with high ability to inhibit bacterial growth.

Table (1 ): shows the Inhibition Zones Induced by concentrated camel urine.

\begin{tabular}{|l|l|}
\hline Bacteria & Zone of inhibition \\
\hline Ps. aeruginosa & $32 \mathrm{~mm}$ \\
\hline E. coloacae & $32 \mathrm{~mm}$ \\
\hline Salmonella sp & $31 \mathrm{~mm}$ \\
\hline E. coli & $30 \mathrm{~mm}$ \\
\hline Staphaureus & $30 \mathrm{~mm}$ \\
\hline
\end{tabular}

Sensitivity of camel urine using $100 \%$ concentrations without any treatment for the urine to tested bacteria resulted in slightly narrow zones of inhibition.

But after neutralization of camel urine by HCL (10\%), there were clear zones of inhibition especially on Pseudomonas.

These zones inhibition were observed after 24 hours after incubation. 
Antimicrobial activity of Camels (Camelusdromedarius ) and Sheep urine on some pathogenic ..

Table (2) shows the inhibition zones before and after neutralization of camel urine.

Bacteria Zone of inhibition before and after neutralization camel urine

$\begin{array}{lcr}\text { Ps. aeruginosa } & 23 \mathrm{~mm} & 24 \mathrm{~mm} \\ \text { E. cloacae } & 18 \mathrm{~mm} & 22 \mathrm{~mm} \\ \text { Salmonella.Sp } 14 \mathrm{~mm} & 17 \mathrm{~mm} & \\ \text { E. coli 14mm } & 15 \mathrm{~mm} & \\ \text { S. aureus } & 12 \mathrm{~mm} & 13 \mathrm{~mm}\end{array}$

Agar well diffusion showed clear zone more than Disc diffusion Methods when tested the organism with the concentrated camel urine.

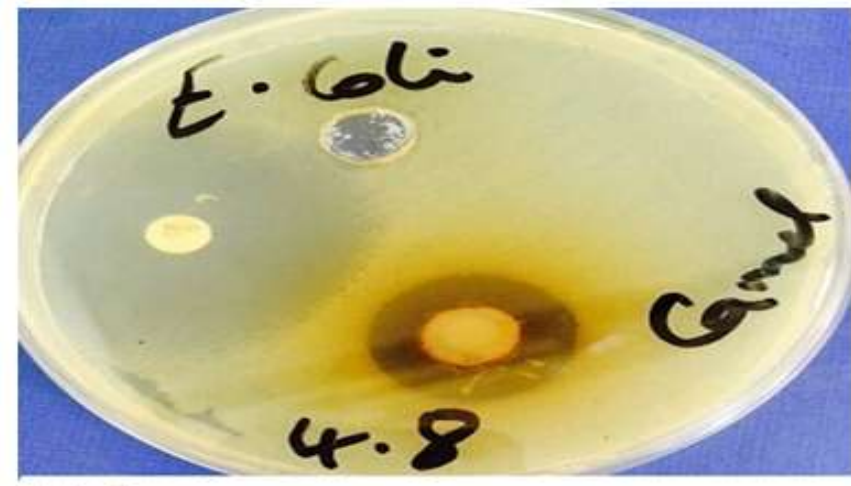

Fig 1:

sensitivity of concentrated came1 urine $(20 \%)$ to $E$. coli

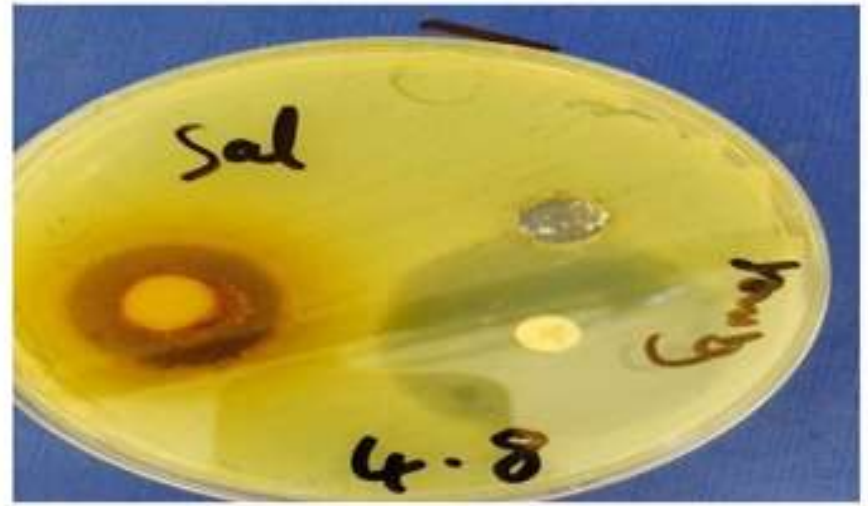

Fig 2:

sensitivity of concentrated eamel urine $(20 \%)$ to Salmonella sp.

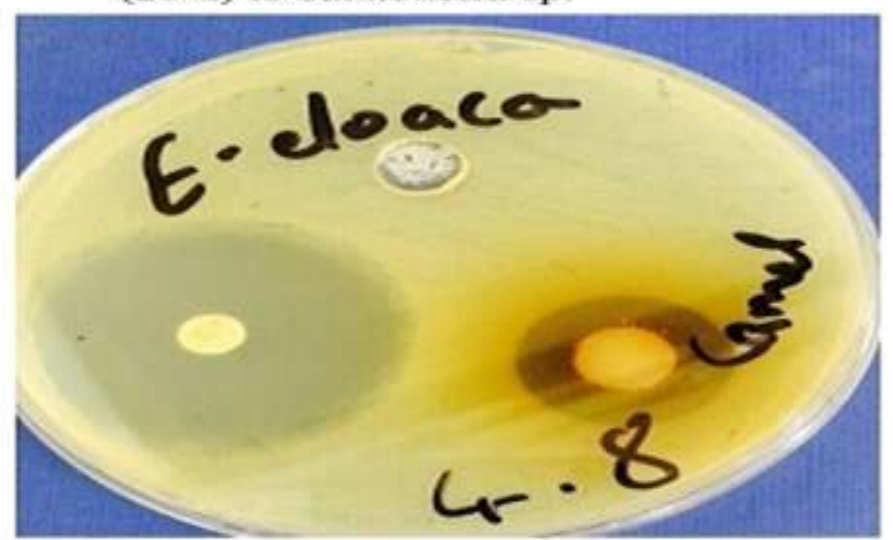

Fig 3:

sensitivity of concentrated camel urine $(20 \%)$ to $E$. cloaca. 


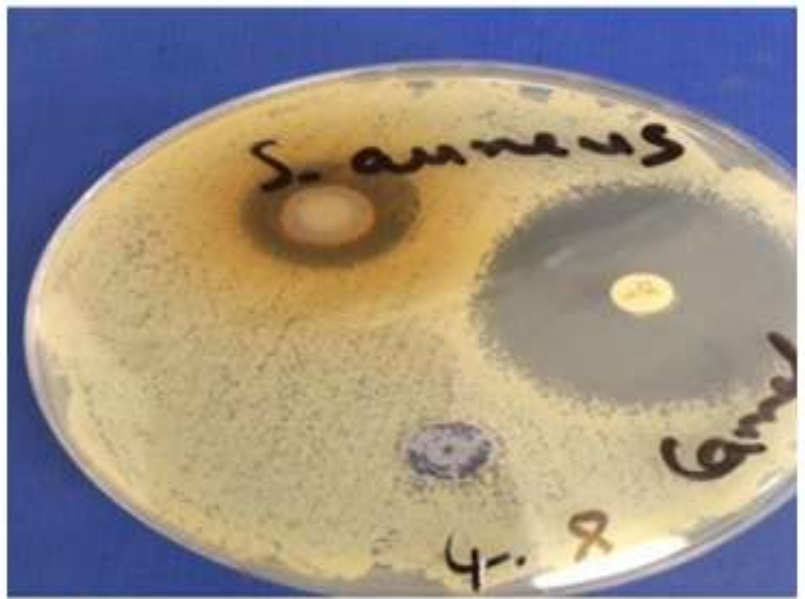

Fig 4:

sensitivity of concentrared(20\%) camel urine to s.aureus.

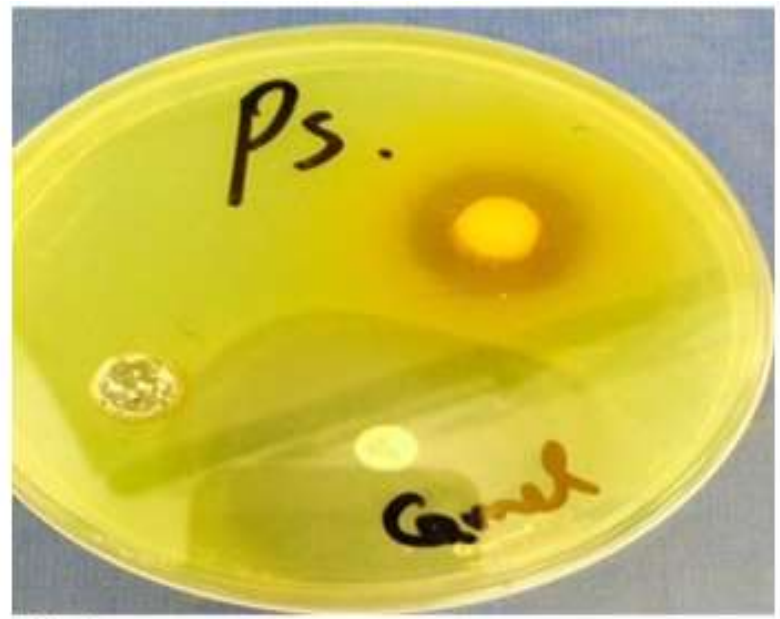

Fig 5:

senitivity of concentrared camel urine to Ps. aeruginosa

The zones of inhibition were more wider when the concentrated camel urine mixed with antibiotic disc in the same well as shown in (Fig6).

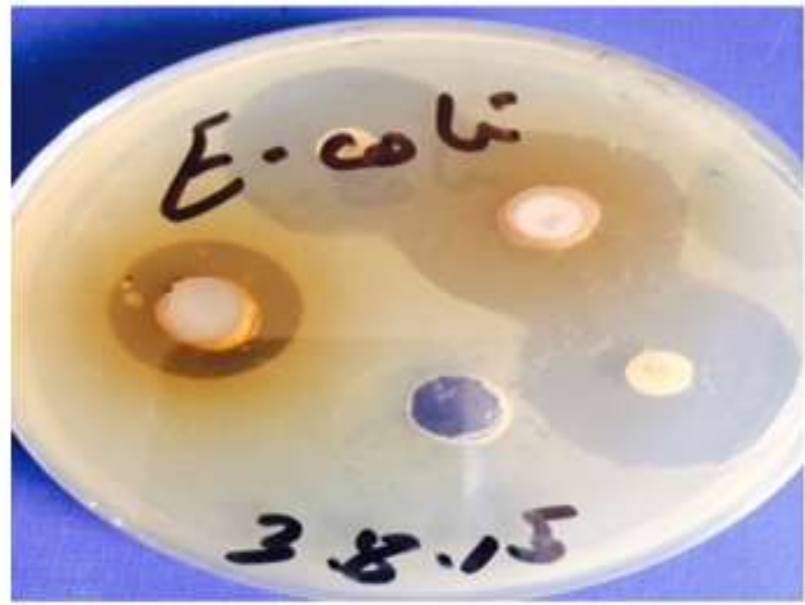

Fig 6:

comparizion between zones of inhubision of pure camel urine and mixed camel urine with antbiobic to $E$. colv. 
No clear result seen in concentrated sheep urine (Fig 7).

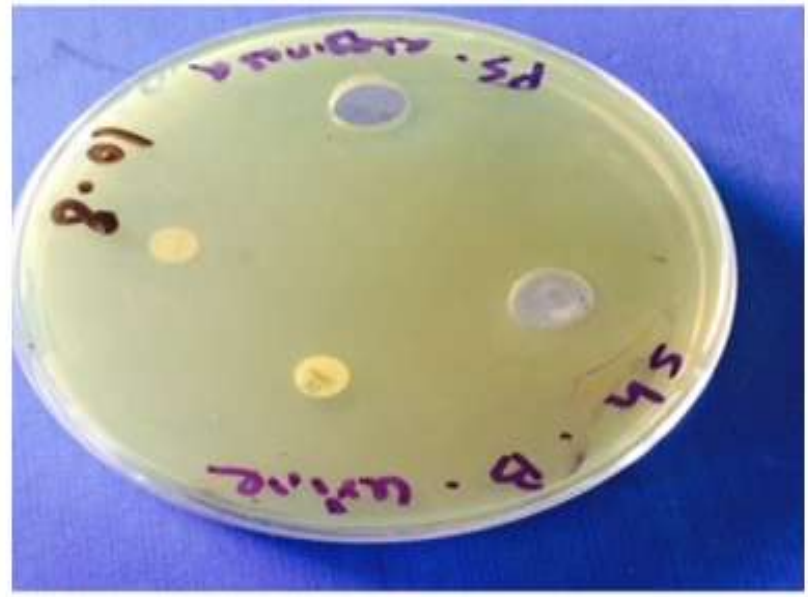

Fig 7:

sensitivity of concentrated sheep urine (20\%) to Ps. aeruginosa showing no inhibitary zone.

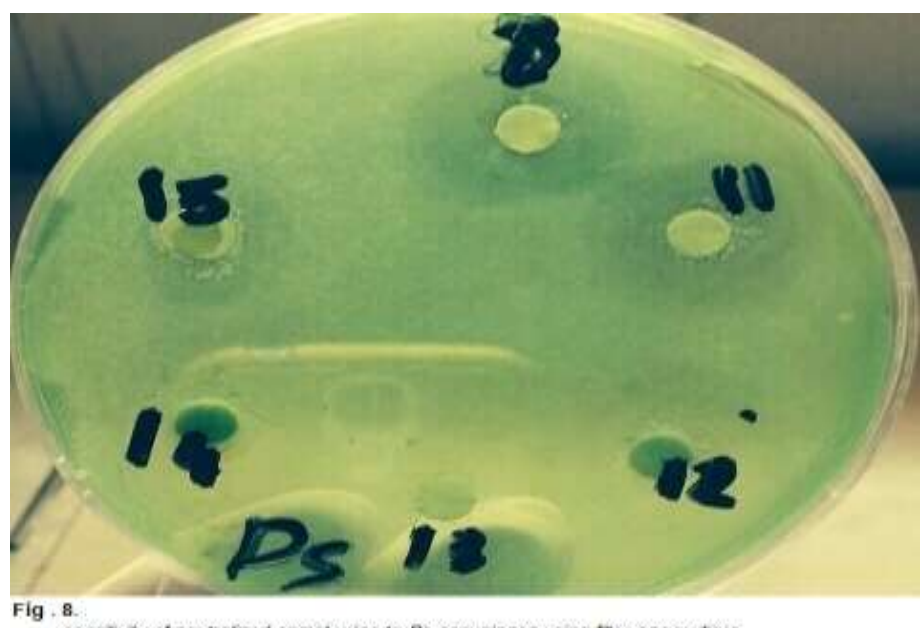

sensasvity of neutralized camel urine to $P$ s. aeruginosa using ther paper discs.

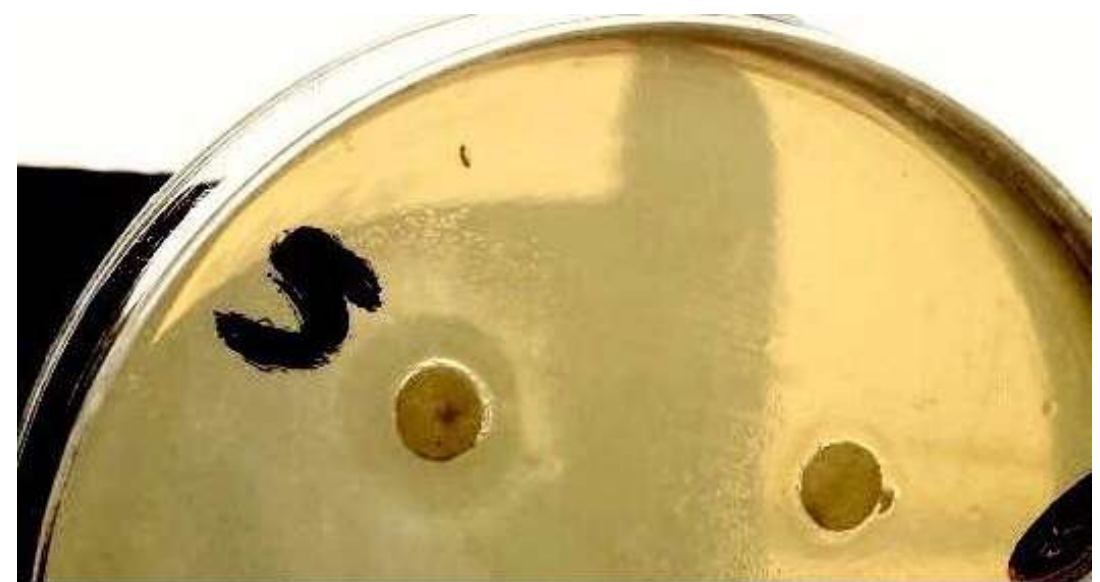

Fig. 9.

sensifvity of camel urine to $\mathrm{s}$. aureus using fiter paper discs

\section{Discussion}

Natural products play an important role in our healthcare system; treatment with camel urine has no side effects. Camel urine concentrated more than sea water this may refer to salty plant found in desert that Camels were fed on in this study camel urine results in positive antimicrobial effect on Pathogenic bacteria $: S$. arueus, Salmonella sp, Ps. aeruginosa, E.coli and E.cloacae, this is similar to Ohaj who mention that camel 
Antimicrobial activity of Camels (Camelusdromedarius ) and Sheep urine on some pathogenic ..

urine had anti-bacterial, antifungal antiviral, antineoplastic and therapeutic applications on ascetic [9], It could be concluded that camel urine proved to has an anti-microbial activity as natural and satisfactory for using as medical treatment [10,11,12]. This study proved that camel urine at low concentration has no significant Inhibitory effect on bacteria, while can be obviously effective after using high concentration, this is in agreement with Aisha [13] . This antibacterial activity may be attributed to antimicrobial components of wild plants and forages which camels were fed on, this explanation agree with many researchers who studied on a variety of desert plant like wormwood and its strong effect against bacteria, yeast and fungi [14].

In this study high inhibitory zone $(32 \mathrm{~mm})$ of Ps. aeruginosa was reported, this was important because this bacteria progress virulence and have limited susceptibility to antimicrobials, also can develop resistance to antibacterial so increasing resistance to different antibiotics has been reported worldwide [14, 16]].

Zones of inhibition were more clear after $48 \mathrm{hr}$, this may be due to positive relation between period of incubation and increasing of the antibacterial activity .This agrees with Munir [12].

It was observed clearly in this study that urine samples of female camel were more effectiveness than urine of male camel.

Zones of inhibition were clearer after neutralization of camel urine. This is agrees with Muna [16] . The zones of inhibition was more wider when the concentrated camel urine was mixed with antibiotic disc in the same well as shown in (Fig 6), as some investigators observed that the antibacterial effect using scanning electron microscope showed crumple and abnormality of treated cell wall with camel urine for all tested bacteria. This may increase the permeability of the cell wall to antibiotic [12].

Active compounds from plants that camel were fed on excreted into the urine and increase antimicrobial activity, these desert plants include Haloxylonaphyllum, H.persieum, Salsolagenmmaseen, S.orientabs, Astraglus ,Aristida, A.pennate,Citrulluscolocynlhisschrad, Acacia eherenbergianahayne ,Dipterygiumglaucum , Convolvulus hystrixvahl ,Rhyzyastrica , Decne and Anabasis setifeferaMog [15, 17 ,18]] . Camels spend more than $80 \%$ of their total feeding time on dicotyledons [17,19], which have more extracellular compounds compared to plants eaten by Cattle, Goat and Sheep . Camels also graze on variety of plants including thorny shrub, halophytes and aromatic species that avoided by cattles, goats and sheep [20], which ensures that active compounds such as flavoids, alkaloid and phenolic are excreted in the urine [21,22, 23].

The results of inhibition of bacteria using concentrated camel urine in our study were in agreement with other authors [14, 23, and 24].

Several studies determined the effect of camel urine on the cells and the results showed the efficient as repaired to the damage cells, including the tumer cells and can be used as anticancer and antiplatelet activity against ADP -induced agent [25,,26,27, 28$]$.

Kidney ,liver and stomach tissues infected with Echerichia coli in mice recover with no histopathological effects after treatment with Camel urine [29] .

Al-awadi and al-jedabi (2000) recorded inhibitory effect on the dry weight of the yeast and fungi. The high salt concentration of the urine causes plasmosis analysis of mycelium hyphae .

Shoeib and Ba-hatheg (2008) proved through electromicroscopicstudies, the effect of urine on the morphological properties of some human pathogenic bacteria.

High inhibitory growth of the tested fungi, were grown in acidic environment, was due to the high alkalinity of camel urine as a result of high concentrations of $\mathrm{K}, \mathrm{Mg}, \mathrm{Ca}$ and proteins , and low concentrations of carbohydrate and cellulose[17, 23 ].

\section{Conclusion}

Camel urine has distinct ability to inhibit the bacterial growth.

Concentrated camel urine was reported as the best preparation of camel urine with high ability to inhibit bacterial growth.

Heating may increase the concentration of active compounds in urine .

The zones of inhibition were wider when the concentrated camel urine was mixed with antibiotic disc in the same well.

Agar well diffusion was reported as better method than Disc diffusion method.

No clear zones were seen when using concentrated sheep urine as an antimicrobial.

\section{References}

[1]. Majid A A. The one-humped Camel (Camelus dromedaries). And human health.The 2nd annual conference the faculty of Grduate Studies. University of Khartoum, Friend Ship Hall, Khartoum., 2011.

[2]. Muna E. Ahmed, Abdalla E. Ahmed andHadya E. Ahmed. Bacteria Associated with Healthy Sudanese Camels' Urine and Drugs Susceptibility of Some Bacteria of Human Origin to Camel Urine. Sudan J. Vet. Res. (2008), 23: 79-82.

[3]. Anwar EL-Shahawy, Nagwa M E, Wadidah S B, Faten K and Neveen S G. Spectral Analysis, Molecular Orbital Calculations and Antimicrobial Activity of PMF-G Fraction extracted from PM-701 1 Biochemistry www.ijpbs.net.. 2010; V1 (2) 
Antimicrobial activity of Camels (Camelusdromedarius ) and Sheep urine on some pathogenic ..

[4]. Vuorela P, Leinonen P, Leinonen M, Saikku P, Tammcla P, Rauha J. Wennbery T, Vuorela H. Natural Products in the process of finding New Drug candidates current medicinal chemistry., 2004.

[5]. O'haj HM. Camel urine as medicament in Sudan. B.Sc Dissertation) University of Gezira Sudan., 1993.

[6]. Buxton A, Fraser G. In animal Microbiology Volume.BlackwellScintific publications Oxford London, Edinburgh, Mebourne., 1977.

[7]. Kirby WM, Brodie JL, Benner. Simplified,accurate method for antibiotic assay clinical Kiby Department of Microbiology and medicine. University of Washington, School of medicine scatle, Washington 98/05. Microbiol.,1966 : 14(2):170-177.]

[8]. Perez ,C.,Paul ,M ,.Bazerque ,P.(1990): An antiboitic assay by the agar well diffussin method . Acta .Bio .Med .Exp . $15: 113-115$.

[9]. Ohaj HM. Clinical trial for treatment of ascitis with Camel urine M.Sc. University of the Gezira, Sudan. 1998.

[10]. AL Awadi A AL Judaib A. Antimicrobial agents in Camel urine (9B) microbial Viruses. 2000; 8: $256-218$.

[11]. Al-Talhi AD, Albashan MM. Microbiologia and Chemical studies on Camel's urine at Taif City .In the Procceedings of the International Scientific Conference on Camels, Under the Patronage of His royal Highness Prince Sultan Bin Abdulaziz Al-Saud, Part 2, 10-12 May 2006, Ministry of Saudi Arabia, Qassim University, Collage of Agriculture and Veterinary Medicine, Kingdome of Saudi Arabia., 2006; pp: 533-522.

[12]. Munir Mustafa Al-Bashan. In vitro Assessment of the Antimicrobial Activity and Biochemical Properties of Camel's Urine Against Some Human Pathogenic Microbes., 2011; 947-958

[13]. Aishea M. Ba.Hatheg.Antibacterial.Effect of Camel urine on some pathogenic bacteria.Department of Botany and Microbiology, King Saud University.., 2006.

[14]. Zaki D, Abd El-Aziz M, El-Gengeihy S, Morsi N. Antimicrobial potentiation of some Egyptian desert plant. HerbaHungarica., $1984 ; 23,73-84$.

[15]. Loureivo MM de Moraes AB. Mendoca VLF (pseudo monas aeruginosa . study of Anti-biotic resistance and Molecular typing in hospital cases in a lveonatal intensive care unit from Rio JanieroCityll. Brazil memories do institute O Cruz 2002, 3:387-394.

[16]. Muna E A. Studies on Sudanese Camel Urine .M.Sc.Thesis Department of Microbiology and Parasitology .Unviresity .of Khartoum., 2003.

[17]. Rutagwenda T, Lechner-D M, Schwartz HJ, Schultka W, Von E W. Dietary preference degradability of forage on a semiarid thornbush savannah by indigenous rumainantsCamel,s and donkeys, Animal feed Science and Technology., 1990; 31: 179-192

[18]. Al-yahya MA, Hifnawy MS, Mossa J, Al-MeshalIA ,Mekkawi A. Aromatic plants of Saudi Arabia. Part 7: Essential oil of Plectranthustenuiflorus Proc.8sumb. Saudi Arabia. Saudi BiolSoc (Al-Hassa)., 1985; 147-153.

[19]. Mukasa-M E. The Camel (Camelusdromedairus), a bibioraphicalreview.The International Live Stock for Africa.ILCA Monograph. No 5 Addis Ababa.1981.

[20]. Iqbal A, Khan BB. Feeding Behavior of Camel, Review. Pak J AgriSei., 2001; 38: 58-63

[21]. Murthy GS, Bagyaraj DJ. Falvonol and alkaloid content of pigeon pea cultivars resistance and suscepstible to fusariumadum. Indian phytopthol., 1981;33: 633-634.

[22]. Tsankova ET, Trendafilova AB, Kujumgiev AI, Galabov AS, Robeva PR. Xanthanolides of Xanthium italicumMoretti and thier biological activity. Z Naturforsch C., 1994; 49: 154-155.

[23]. Ahlam Al-Awadi and Awatif Al-Judaibi. Effect of Heating and Storage on Antifungal Activity of Camel urine Department Biological Science, Microbiology Section, King AbdalazizUnivercity, Jedda, KSA, Saudi Arabia. 2014.

[24]. Abed-rahman A. Humaid. Antagonistic effect of camel urine on some pathogenic bacteria species .Department of Biolog ,Faculty of science ,Sana a , University . Sana a ,Yemen. 2016.

[25]. Muhammad AM. A study of the chemical composition and some medical uses of the urine of Arabian camels, Al-Jazeerah university thesis., 1998.

[26]. Al-Yousef N, Gaafar A, AL-Otaibi B, AL-Jammaz I, AL-Hussein K, Aboussekhra A. Camel Urine components Display anticancer properties in Vitro.Gournal of Ethnopharmacology., 2012; 143:819-825

[27]. EL-ELyaniRAA,Kalifa SAM. Histological Studies on the effect of Camels Urine-and Milk on stomach of Albino Mice .Saudi Biolo Sci., 2006; 13;2 .

[28]. AlhaindarA ,Abdel Gader AM , Mousa SA. The Journal of Alernative and Complementary Medicine., 2011; 17:803-808 .

[29]. KhalifaS , Al-Elyani- R .AL ,ALwani (2005) Histological ,Cyto logical and Histochemical Studies on effect of Camel urine on liver of Rabbits infected By Escherichia coli . Saudi J BioloSci12:66 -80 